\title{
Leadership Effectiveness and Organizational Performance: Exploring Gaps in the Existing Literature
}

\begin{abstract}
Alam Zeb ${ }^{1}$, Shabir Ahmad ${ }^{2}$, Gohar Saeed ${ }^{3}$
Abstract

This study aims at investigating the gaps in the existing literature in relationship between leadership effectiveness and organizational performance. Based primarily on an in-depth review of substantial literature, the study reveals that existing research concerning leadership effectiveness is mostly ethnocentric in nature as majority of these studies have been conducted in western countries suchas America, United Kingdom, France and Germany and replicated in other countries without considering the particular culture, situation and context. These studies have overlooked contextual realities and cultural effects in the relationship between leadership effectiveness and organizational performance. Similarly, limited aspects have been considered in the measurement of leadership effectiveness and organizational performance in existing research. Due to this, there is lack of clarity in understanding the relationship between leadership effectiveness and organizational performance. It argues that the relationship between leadership and organizational performance is not simple one that can be measured through simple linear relationship. There is a complex relationship having different aspects and dimensions that make it difficult to get specific conclusions regarding leadership effectiveness and organizational performance.
\end{abstract}

Keywords: Gaps, leadership effectiveness, organizational performance, relationship

\section{Introduction}

Organizational performance is contingent upon effective leadership (Drucker, 1964; Khan, 2002). This conviction is evident from the fact that the relationship between leadership and organizational performance has remained the focus of researchers for last four decades (Cannella \& Rowe, 1995). Although considerable research has been conducted on this topic, the phenomenon of effective leadership

1 Assistant Professor, Department of Management Studies, University of Malakand.

Email:alamzebmbams@gmail.com

2 Assistant Professor, Department of Management Studies, University of Malakand.

3 Field Researcher/Deputy director, Pakistan Academy for Rural Development, Peshawar.

\section{ARTICLE HISTORY}

24 Nov, 2017 Submission Received

8 Dec, 2017

First Review

28 Feb, 2018 Second Review

$28 \mathrm{Feb}, 2018$

Revised Version of Both Reviews

10 Mar, 2018 Accepted 
and its relationship with organizational performance is still obscure. A review of various studies such as research conducted by Analoui (1999), Avery (2004), House and Aditya (1997), Shamir and Howell (1999) and Yukl (1999) suggest that there are limitations, difficulties and unsolved problems associated with the relationship between leadership and organizational performance. In addition, there are methodological and contextual problems that have made it difficult to get specific conclusions regarding leadership effectiveness and organizational performance.

Similarly, studies carried out by Hofmann and Jones (2005), Keller (2006) and Lim and Ployhart (2004) show that previous research has focused on limited aspects of organizational performance such as financial performance and non-financial performance. These studies have overlooked various aspects such as employees' satisfaction, technological aspects and government and community support. This shows that there are a number of limitations in the measurement of organizational performance.

Due to the above mentioned problems in the studies of leadership and organizational performance, it can be aptly stated that there are numerous limitations in the studies regarding relationship between leadership and organizational performance. Thus, there is limited evidence that can elaborate issues and problems in existing literature of leadership effectiveness and organizational performance. This shows a clear gap in the existing literature. This research study is an attempt to identify the prevailing gaps in the existing literature and to provide in-depth knowledge and information to researchers regarding the issue under investigation. The findings of this study will identify those areas that have been overlooked in the existing studies and will broaden the understanding of researchers regarding the unresolved problems and issues in the studies related to leadership effectiveness and organizational performance.

\section{Literature Review}

The role of an effective leader is vital for organizational performance (Sirisetti, 2011). Effective organizational leaders develop progressive organizational cultures, develop employees' motivation, clarify vision and organizational objectives, and guide the whole efforts towards high performance and outcomes (Sirisetti, 2011). This is due to the instrumental role of effective leaders who safeguard organizations' benefits by realizing the needs of the employees and integrating all the resources for achieving organizational goals and objectives (Sansom, 1998). Evidence shows that leadership is not only a set of directives and orders issued by a boss and obeyed by subordinates, it is a collective ability and wisdom of the team to safeguard the organization's benefits by realizing the needs of the employees and understanding the targets and integrating all the resources in order to achieve common goals (Kahn, Barton, \& Fellows, 2013). Since the start of the new millennium, the effectiveness of leadership is conceptualized 
as an interactive nature of social systems (Valcea, Hamdani, Buckley, \& Novicevic, 2011). Effective leadership is an interactive process of environmental knowledge, strategic competence and trustworthiness among subordinates (Byrne et al., 2014). The strategic competence of organizational leaders help to develop a strategic fit between goal and objectives of originations with its external environment (Mhatre \& Riggio, 2014). Similarly, trustworthiness of leadership encourages followers to perceive the validity of the mission (Mhatre \& Riggio, 2014). Thus, effective leadership develops a relationship through which a leader motivates followers to give their best, by providing support for growth and rewarding subordinates fairly, tangibly and psychologically for their efforts. Finally, effective leaders utilize material and psychological resources of themselves and their teams with best strategies for task accomplishment that are adapted to the social and task environment (Lamb, 2013). The importance of organizational leadership is evident from the fact that it has long been a major area of interest among researchers and still continues to attract both academicians and practitioners (Lado, Boyd, \& Wright, 1992). Leadership plays a fundamental role in organizations (Drucker, 1964; Khan, 2002). It is argued that leadership role cannot be undermined in any organization because it deeply influences the organizational performance. Besides this, leadership is viewed by some researchers as one of the key driving forces for increasing organizational performance (Bennis \& Nanus, 1985; Hersey \& Blanchard, 1988). It is argued that an effective leader develops reputation and goodwill of an organization (Vigoda-Gadot, Shoham, Schwabsky, \& Ruvio, 2008). Leadership effectiveness is the basic element that determines the success and failure of organizations (Bennis \& Nanus, 1985; Hersey \& Blanchard, 1988). An effective leader determines the right directions, builds organizational vision, and develops strategies in order to achieve long-term organizational goals and objectives (Northouse, 1997). This shows that the role of effective leadership is crucial in organizations. Therefore, Drucker (1964) considers leadership as a key to success for public sector organizations. It is widely believed that effective leadership leads to effective organizational performance because leadership creates vital links between people, process and procedures in organizations that leads to better organizational performance (Avolio \& Bass, 1991; Judge, Bono, Ilies, \& Gerhardt, 2002; Keller, 2006; McGrath \& MacMillan, 2000; Yukl, 1999).

Ali (2007) summarizes that role of an effective leader is blending of motivational, strategic and managerial skills. Leaders use energy in a strategic way to inspire and motivate a team towards achieving a common task. Similarly, effective leadership is believed by some scholars as a basic requirement for facilitating and improving organizational performance. It enables organizations to face challenges (McGrath \& MacMillan, 2000; Teece, Pisano, \& Shuen, 1997). 
An effective leader continuously addresses fundamental public policy issues of poverty, education, housing, security and health effectively. They demonstrate public agenda and grapple with dilemma of how governments can remain credible and focused when significant resources are not in their control or organizations are assigned to political people with limited ability. The key role of leadership is to construct required institutional and human resources for the purpose of developing capacities of individuals to support effective governance. Effective leadership in public sector organizations is required to promote a culture where main duties of a leader should be the development of strategic vision and planning. This usually leads to the desired change which is characterized by managing knowledge, internalizing quality, entering the digital age, building partnerships, managing for accountability and getting right values and ethics. For this purpose, one of the fundamental roles of a leader inside organization is to guide employees and provide them direction. Leaders motivate their employees through inspiration, develop team work through mutual trust and focus upon the results (Covey, 2003). This helps in directing subordinates to exert efforts towards achieving organizational goal. In spite of fundamental importance of various factors in organization such as human force, process, procedure and material, success and failure of an organization is contingent upon leadership effectiveness where employees are motivated and willing to spend energy and effort to ensure success (Cornelius, 2004). Nasseh (1996) goes on to suggest that leaders need motivational skills in order to play their fundamental role. Motivation is the force that can change the mind of the employees. According to Buford, Bedeian, and Lindner (1995), motivated subordinates exert more efforts for achieving organizational goals. Hence, leaders are required to motivate subordinates by their recognition and public praise, assigning them challenging job, good working relation, empowerment and handsome remuneration and incentives (Nasseh, 1996). Mathews (2004) adds that leaders can motivate employees if they provide clear direction, good chemistry, favorable working environment and opportunity for their growth and development. These help increase subordinates motivation. Motivation of subordinates can also be developed by making their job interesting (Raees, 2004). Raees (2004) further explains that jobs are interesting if there is feedback, lots of skills, autonomy, mine and effect. The author further explains that feedback is essential for job motivation and it comes through peers or supervisors, lots of skills mean employees use a variety of skills for achieving organizational goal and objectives, autonomy activates employees to take proactive steps on their own in bringing improvement in their work activities and finding solutions to the problems, mine gives sense of ownership to the employees such as my work, my project and my goals and objectives and effect on others shows that how much the work affects others (Raees, 2004). Leight and Maynard (1999) argue that one of the important roles of effective leader is to inspire their followers. Effective leaders inspire their subordinates (Barnett, McCormick, \& Conners, 2001). This is important 
for followers' motivation (Bass, 1985) because inspiration develops enthusiasms in a hopeful manner that is essential for putting more energy in performing duties. This develops the followers' confidence and commitment and optimizes their efforts and contribution in achieving organizational goal and objectives. Therefore, organizational leaders need to be capable in developing an environment of trust among their colleagues. This requires leader to be proficient and behave as a role model (Dran, 2004). Effective leaders motivate their employees by setting personal examples. Dran (2004) suggests that leader should perform as a role model and should set personal examples of good attitude, behavior, working relations, manners and performance. Kunich and Lester (1999) consider organizational leaders as key figures. Organizational leaders need to develop dignity, integrity and professionalism. Therefore, Cook (2004) suggests that positive behavior, values and consistency in behavior make a leader role model for his team. These behaviors develop leader credibility in team and subordinates get inspired (Kouzes \& Posner, 1987).

Another important role of a leader is team building (Brin, 1998). Effective leaders develop their teams in organizations. For this purpose, leaders acknowledge subordinates for their achievements. This encourages each member of the team due to which they share their problems, accomplishments and other important matters. This leads to improve organizational capacity. If a leader does not encourage contributions of the team there is likelihood that the team loses its spirit (Covey, 2003). Team is constituted by its members but the leader plays a key role in developing a climate for the development of team (Bacal, 2004).

Effective leaders act as a catalyst in an organization for change and innovation. According to Siu and Glover (2001), the working environment in some organizations especially in public sector organizations is conventional which does not allow leaders to apply the newly learnt skills and ideas in the real working atmosphere. Due to this situation, the role of organizational leadership has been undermined. In these circumstances, leaders face resistance to adopt necessary changes that are required and resultantly they cannot update the organizational system. Evidence shows that a key role of effective leaders is their ability to adapt change (Baron, 1995). As long as an organization grows up, its leaders need to adopt changes (Horner, 2004; Baron, 1995). In this regard, effective leader is considered as change agent (Dran, 2004) where leaders should encourage the new learning skills and abilities of its members. However, according to Ristino (2005), change in organization is depended on the leaders' vision because visionary leaders are clear and understandable and guide the whole efforts in one direction. In another study, Senge (2006) writes that a visionary leader is the one who can predict the impact of creative efforts in the organization. Evidence shows that organizations having visionary leaders lead towards growth and 
success (Zhu, Chew, \& Spangler, 2005; Gill, 2006).

According to Dran (2004), leadership is a process by which goals and directions are set by one person for their group. The leader thus influences or acts with competence and dedication to realize set goals (Senge, 2006). Effective leaders set goals and objective effectively communicate it to subordinates. Subordinates are informed with the importance of the goals. This helps in developing collective trust to achieve organizational goals (Kunich \& Lester, 1999). In case, the goals are not properly communicated, this creates role ambiguity that further leads to develop conflicts in achieving goals and objectives (Payne, 2005). Goals setting help in minimizing time duration of problem solving and decision making. Its clarification helps them focused and cooperative. Therefore, effective communication is one of the fundamental characteristics of an effective leader. It is argued that effective communication is an important factor in the success of an organization (Hargie, Tourish, \& Hargie, 1994) because this develops a sense of direction and connectivity among members of an organization.

Thus, in summarizing the role of leadership, researchers have defined organizational leaders as vision and mission builders (Mhatre \& Riggio, 2014; Zhu et al., 2005 ), motivator (Covey, 2003), team builders (Ulrich, Smallwood, \& Sweetman, 2008), participative decision makers (Gamage \& Pang, 2003; Northouse, 1997) and role model (Dran, 2004). 'In addition, leaders need to have effective communication skills (Anderson, 2006); the ability to develop trust (Byrne et al., 2014; Kouzes \& Posner, 1987) and the will to recognize achievements (Bolman \& Deal, 2003). This shows that effective leaders have to perform a combination of several important roles for which they need potent combination of several characteristics.

However, deeper insight into the literature shows that there are various issues such as cultural, social and methodological problems in studies regarding leadership effectiveness and organizational performance.

The following section elaborates different problems in studies regarding leadership effectiveness and organizational performance.

\subsection{Ethnocentric nature of existing studies}

One of the dominant problem in studies regarding leadership effectiveness and organizational performance is ethnocentric nature of these studies. Evidence shows that a considerable number of studies about leadership and organizational performance have been conducted in the United States and various European countries and these have been replicated in numerous other countries without taking into account its particular socio-economic, political and cultural contexts (Adler, 1984). 
In this regard, indigenous studies in the context of developing countries are very few except research conducted by Misumi's (1985) seminal research work in Japan, Sinha's (1980, p. 85) nurturant task oriented model in India and the prophetic Caliphal model of leadership developed by Khadra (1990) in Arab countries. This shows that there is considerable gap in the existing studies regarding leadership effectiveness for not considering particular culture and context. Beside this, there is lack of universal theories and precise formulas that can explain the concept of effective leadership and its relationship with organizational performance. A review of one hundred and twenty four studies was published by Stogdill in 1948. Researchers in these studies identified certain general characteristics of effective leadership such as initiatives, social dominance and persistence but no common characteristics or traits identified that can reflect uniformity in the studies about leadership effectiveness. However, there is dearth of studies having focused on contextual factors in the measurement of organizational performance. There is lack of cultural sensitive models of leadership and organizational performance (Smith \& Peterson, 1994). This is due to the reason that a number of tools and instruments have been developed for measuring leadership effectiveness such as Leader Behavior Description Questionnaire (LBDQ) developed by Ohio State University, Multi-factor Leadership Questionnaire (MLQ) developed by Bass (1985) and his colleagues and the Leadership Practices Inventory (LPI) developed by Kouzes and Posner (1887). All these models and measuring instruments have been developed in the west and are based on western models of leadership. Hence, these models have overlooked various aspects of contextual realities in developing countries due to which research on the relationship between leadership and organizational performance is not conclusive. There are many unresolved methodological problems. Thus, conclusions cannot be drawn about the extent to which leadership effectiveness and organizational performance are considered linear and interdependent on each other.

\subsection{Lack of understanding complex nature of leadershi $p$ and organizational performance}

Evidence shows that there is a debate amongst theorists regarding complex nature of leadership phenomenon (Barrow, 1977). It is argued that leadership effectiveness in not a simple phenomenon (Barrow, 1977). It is a complex process having different aspects and dimensions (Barrow, 1977). Stoian (2009) elaborates that leadership effectiveness depends on different aspects and dimensions such as characteristics of a leader and the situation in which he/she operates as the behaviors of a leader at times depends on the conditions and forces present in a given situation. There are various dimensions that can define the degree of leadership effectiveness such as in present times visionary, transformational and charismatic leadership has gathered a 
considerable attention (Conger \& Kanungo, 1987; House \& Aditya, 1997). Similarly, strategic leadership articulate that behavior of a leader affects organizational performance. Existing evidence illustrates that researchers have mostly focused the leadership effectiveness from behavioral, personality trait, vision and genetic (by birth) aspects (Jing \& Avery, 2008). They have either ignored or narrowly discussed cultural and social aspects of leadership effectiveness. This has also created problems in measuring the relationship between leadership effectiveness and organizational performance.

Besides this, numerous methods have been used by researchers for organizational performance. In this regard, Delany and Huselid (1996) adopted perpetual measures of organizational performance and Terpstra and Rozell (1993) suggested financial measures such as profit and financial ratios. However, organizational performance cannot be measured through simple linear relationship (Chenhall \& Smith, 2007). It has different aspects and dimensions that need to be taken into account. Chenhall and Smith (2007) developed Organizational Performance Index (OPI) for measuring organizational performance. This is based on multiple performance indicators such as Marris Ratio, Tobin's Q, return on equity, return on assets and perceived organizational performance. This measurement of organizational performance clarifies the internal and external picture of organization performance measurement. However, there is lack of empirical studies that can suggest other variables such as customers' satisfaction, employees' satisfaction and so on. This is important for the overall measurement of financial performance (Charreaux, 1997). Performance measurement of organization is a complicated matter and needs to be measured with regard to shareholder or stakeholder value maximization as well. Due to this, over the years measurement of organizational performance has been a matter of great debate among researchers. Therefore, Hoogh et al. (2004) argues that research conducted in the past has been criticized for the measurement of organizational performance. In the organizational performance measurement, limited aspects such as outcome aspect of the organizational performance have been considered rather than other important aspects such as financial performance, customer satisfaction and employee satisfaction (Keller, 2006; Lim \& Ployhart, 2004). Most of the existing studies have adopted either financial measurements or non-financial measurements rather than using both. This shows insufficient measurement of organizational performance.

In view of the overall discussion, the following conclusion can be drawn.

\section{Conclusion}

This paper has critiqued literature concerning relationship between leadership effectiveness and organization performance. By reviewing vast literature on the subject, the paper argues that there are various gaps in the existing studies concerning 
relationship between organizational performance and effective leadership. It posits that neither leadership effectiveness nor organizational performance are linear and straightforward phenomenon but both are quite complex and multifaceted concepts and the relationship between the two can only be properly understood after taking into account numerous contextual factors.

Effective leadership is a complex social phenomenon. It is totally context based and situation dependent. Therefore in-depth investigation is required by adopting interpretevist approach and qualitative methodology.

Many studies have been conducted on leadership effectiveness in the developed countries like Europe, America and Australia and different leadership models have been developed. But these models are not appropriate to be used in the developing countries like Pakistan, India, Bangladesh and different other Asian countries. Therefore, indigenous models of leadership are needed to be developed in the different areas and countries based on particular context and situation.

In many studies few leadership paradigm have been focused such as transactional and transformational and other paradigms have been ignored such as classic and organic. This has created a gap between some important aspects of the leadership. In future research all aspects of the leadership paradigm should be considered comprehensively, so that, the relationship between effective leadership and organizational performance becomes clear.

In order to calculate the organizational performance many studies in the past have considered either financial or non-financial aspects of the organization. This provides very narrow insight on the organizational performance. Therefore, financial and non-financial aspects along with the factors such as quality of product, development of new product or services, employee attraction, employee retention, customer satisfaction, trustful relationship between management and employees, market share, company image in the market needs to be taken into consideration.

\section{References}

Adler, N. J. (1984). Understanding the ways of understandings: Cross cultural management methodology reviewed. Advances International Comparative Management, 1, 31-67.

Analoui, F. (1999). Eight parameters of managerial effectiveness. Journal of Management Development, 18(4), 362-389.

Avery, G. C. (2004). Understanding leadership: Paradigms and Cases. London: Sage. 
Avolio, B. J., \& Bass, B. M. (1991). The full range of leadership development. Binghamton, NY: Center for Leadership Studies.

Bacal, R. (2004). The manager's role: Bacal and Associates Ontario. Canada.

Barnett, K., McCormick, J., \& Conners, R. (2001). Transformational leadership: Panacea, placebo, or problem? Journal of Educational Administration, 39(1), 24-46.

Baron, A. (1995). Going public with studies on culture management. Personnel Management, 1(19), 60.

Barrow, C. J. (1977). The variable of leadership: A review and conceptual framework. Academy of Management Review, 2(2), 231-251.

Bass, B. M. (1985). Leadership and performance beyond expectations. Free Press: NY.

Bennis, W., \& Nanus, B. (1985). Leaders: The strategies for taking charge. New York: Harper Row.

Bolman, L. G., \& Deal, T. E. (2003). Reframing organizations: Artistry, choice, and leadership (3 ${ }^{\text {rd }}$ ed.). San Francisco, CA: Jossey-Bass.

Brin, A. J. (1998). Leadership. Rochester Institute of Technology, USA.

Byrne, A., Dionisi, A. M., Barling, J., Akers, A., Robertson, J., Lys, R., Wylie, J., \& Dupré, K. (2014). The depleted leader: The influence of leaders' diminished psychological resources on leadership behaviors. The Leadership Quarterly, 25(2), 344-357.

Cannella Jr, A. A., \& Rowe, W. G. (1995). Leader capabilities, succession \& competitive context: A baseball study. The Leadership Quarterly, 6(1), 69-88.

Chenhall, R. H., \& Smith, L. (2007). Multiple perspectives of performance measures. European Management Journal, 25(4), 266-282.

Conger, J. A., \& Kanungo, R. N. (1987). Toward a behavioral theory of charismatic leadership in organizational settings. Academy of Management Review, 12(4), 637-647.

Delany, J. T., \& M. A. Huselid. (1996). The impact of human resource management practices on perceptions of organizational performance. Academy of Management Journal, 39(4), 949-969.

Dran, G. V. (2004). Roles of a leader. Sysacrase University. Retrieved from www.ffos. hr/lida 2004/ppt/ subota/LIDA_2004_Gisela_von_Dran.pptleader + roles + in $+h r m \% 22 \& h l=e n \& h l=e n \&$ ie $=U t f-8$.

Drucker, P. (1964). Managing for result. New York: Harper and Row.

Gamage, D. H., \& Pang, S. K. (2003). Leadership and management in education: Developing essential skills $\mathscr{B}$ competencies. Hong Kong: The Chinese University Press.

Hargie, C., Tourish, D., \& Hargie, O. (1994). Managers communicating: An investigation of core situations and difficulties within educational organizations. International Journal of Educational Management, 8(6), 23-28. 
Hofmann, D.A., \& Jones, L. M. (2005). Leadership, collective personality \& performance, Journal of Applied Psychology, 90(3), 509-522.

Hoogh, A.H.B. de., Hartog, D. N. den., Koopman, P. L., Berg, H. T., Berg, P. T. van den., Weide,

J.G. van der., \& Wilderom, C. P. M. (2004). Charismatic leadership, environmental dynamism \& performance. European Journal of Work and Organizational Psychology, 13(4), 447-471.

Horner, M. (2004). Leadership theory reviewed. London: Open University.

House, R. J., \& Aditya, R. N. (1997). The social scientific study of leadership: Quo Vadis? Journal of Management, 23(3), 409-473.

Jing, J. F., \& Avery, C. G. (2008). Missing links in understanding the relationship between leadership and organizational performance. International Business $\mathcal{E}$ Economics Research Journal, 7(5), 67-78.

Keller, R. T. (2006). Transformational leadership, initiating structure \& substitutes for leadership: A longitudinal study of research \& development project team performance, Journal of Applied Psychology, 91(1), 202-210.

Khadra, B. (1990). The Prophetic-caliphal model of leadership: An empirical study. International Studies of Management and Organization, 20(3), 37-51.

Khan, S. (2002). Personal administration with special reference to Pakistan. Lahore: Alameen Publication Press.

Kouzes, J. M., \& Posner, B. Z. (1987). The leadership challenge. Jossey- Bass, San Francisco, CA.

Kunich, J. C., \& Lester, R. (1999). Leadership and the art of mentoring US Air Force. The Journal of Leadership Studies, 6(1/2), 17-35.

Lado, A. A., Boyd, N. G., \& Wright, P. (1992). A competency-based model of sustainable competitive advantage: Toward a conceptual integration. Journal of Management, 18(1), 77-91.

Lamb, R. (2013). How can managers use participative leadership effectively? Retrieved from http://www.task. $\mathrm{fm} /$ participative-leadership

Lim, B., \& Ployhart, R. E. (2004). Transformational leadership: Relations to the five-factor model \& team performance in typical and maximum contexts. Journal of Applied Psychology, 89(4), 610-621.

Mhatre, K. H., \& Riggio, R. E. (2014). Charismatic and transformational leadership: Past, present, and future. The Oxford Handbook of Leadership and Organizations, 14(1), 221-240.

Misumi, J. (1985). The Behavioral science of leadership: An Interdisciplinary Japanese Research Program. University of Michigan Press, Ann Arbor, MI.

Northouse, P. G. (1997). Leadership: Theory and Practice. Thousand Oaks, CA: Sage Publication Ltd.

Payne, H. J. (2005). Reconceptualizing social skills in organizations: Exploring the relationship between 
communication competence, job performance, and supervisory roles. Journal of Leadership $\mathcal{E}$ Organizational Studies, 11(2), 63-77.

Ristino, R. J. (2005). Leadership's role in communicating radical organizational change. Roger Williams University, Bristol RI, USA. Retrieved from http://m05. egpublisher.com/ proposals/314/index_html.

Sansom, G. (1998). Leadership Style. UTS Centre for local Government.

Senge, P. (2006). The fifth discipline: The Art and Practice of the Learning Organization. Century, London.

Shamir, B., \& Howell, J. M. (1999). Organizational \& contextual influences on the emergence \& effectiveness of charismatic leadership. The Leadership Quarterly, 10(2), 257-283.

Sinha, J. B. P. (1980). A model of effective leadership styles in India. International Studies of Management and Organization, 14(2), 86-98.

Sirisetti, S. (2011). Quality leadership in the public sector strategies and challenges. The Journal of Commerce, 3(4), 45-48.

Siu, M. N., \& Glover. L. (2001). Barriers to Effective Managerial Practices in China. Asia Pacific Business Review, 7(3), 57-74.

Smith, P. B., \& Peterson, M. F. (1994). Leadership as event management: A cross cultural survey based upon middle managers from 25 nations. The $3^{\text {rd }}$ International Conference of Applied Psychology, Madrid.

Terpstra D. E., Rozell E. J. (1993). The relationship of staffing practices to organizational level measures of performance. Personnel Psychology, 46(1), 27-48.

Ulrich, D., Smallwood, N., Sweetman, K. (2008). The leadership code: Five Rules to Lead. Harvard Business School Press, Boston.

Valcea, S., Hamdani, M. R., Buckley, M. R., \& Novicevic, M. M. (2011). Exploring the developmental potential of leader-follower interactions: A constructive-developmental approach. The Leadership Quarterly, 22(4), 604-615.

Yukl, G. (1999). An evaluative essay on current conceptions of effective leadership. European Journal of Work $\mathcal{E}$ Organizational Psychology, 8(1), 33-48.

Zhu, W., Chew, I. K. H., \& Spangler, W. D. (2005). CEO transformational leadership \& organizational outcomes: The mediating role of human-capital-enhancing human resource management. The Leadership Quarterly, 16(1), 39-52. 